\title{
DESIGN OF A PINEAPPLE LEAF FIBER DECORTICATOR MACHINE
}

\author{
Nurhikmah Weisdiyanti $^{* 1}$, Kiki Santoso $^{2)}$, Riri Syavira ${ }^{3)}$, \\ Liza Karina Octovyanda Pohan ${ }^{4)}$, Rionaldo Tamba', Rita Juliani' \\ ${ }^{1,2,5,6)}$ Department of Physics, Medan State University \\ ${ }^{3)}$ Department of Chemistry, Medan State University \\ ${ }^{4)}$ PKK, Medan State University \\ e-mail: nurhikmahweisdiyanti@gmail.com \\ julianiunimed@gmail.com
}

\begin{abstract}
The manufacture of pineapple leaf fiber decorticator machines has been made in the village of Onan Runggu III, Sipahutar District, North Tapanuli Regency. Machine making aims to help pineapple farmers to overcome the problem of waste and pineapple. The method used starts from feasibility studies, designing machines, collecting and purchasing tools and materials, evaluating results and testing tools. Results obtained by the pineapple leaf fiber decorticator machine $0,12 \mathrm{~kg} / \mathrm{hour}$ obtained through two stages of grinding namely grinder 1 and grinder 2. The final results obtained from the decorticator machine of pineapple leaf fiber are pineapple leaf fibers that can be used to make raw materials for textile products.
\end{abstract}

Keywords:decorticator machinery, waste, pineapple leaves, textile.

\section{RANCANG BANGUN MESIN DECORTICATOR SERAT DAUN NANAS}

\author{
Nurhikmah Weisdiyanti ${ }^{* 1}$, Kiki Santoso ${ }^{2)}$, Riri Syavira ${ }^{3)}$, \\ Liza Karina Octovyanda Pohan ${ }^{4)}$, Rionaldo Tamba ${ }^{5}$, Rita Juliani ${ }^{6}$ \\ ${ }^{1,2,5,6)}$ Jurusan Fisika, Universitas Negeri Medan \\ ${ }^{3)}$ Jurusan Kimia, Universitas Negeri Medan \\ 4) PKK, Universitas Negeri Medan
}

\begin{abstract}
Abstrak
Mesin decorticator serat daun nanas telah dirancang di Workshop Teknik Unimed. Pembuatan mesin bertujuan untuk membantu petani nanas di desa Onan Runggu III, Kecamatan Sipahutar, Kabupaten Tapanuli Utara dalam mengatasi masalah limbah dan nanas. Metode yang digunakan mulai dari studi kelayakan, merancang mesin, mengumpulkan dan membeli alat dan bahan, mengevaluasi hasil dan alat pengujian. Hasil yang diperoleh oleh mesin decorticator serat daun nanas $0,12 \mathrm{~kg} / \mathrm{jam}$ diperoleh melalui dua tahap penggilingan yaitu penggiling 1 dan penggiling 2 . Hasil akhir yang diperoleh dari mesin decorticator serat daun nanas adalah serat daun nanas yang dapat digunakan untuk membuat bahan baku untuk produk tekstil.
\end{abstract}

Kata kunci: Mesin decorticator, limbah, daun nanas, tekstil.

\footnotetext{
${ }^{1)}$ Komunikasi Penulis
} 


\section{Pendahuluan}

Nanas atau Ananas Comosus Merr merupakan tanaman semak yang berasal dari sebutan orang Tupi yaitu ananas yang berarti buah yang sangat baik. Salah satu komoditas yang memiliki potensi bisnis yang cukup besar untuk mencapai sasaran adalah agroindustri pengolahan serat alam daun nanas.

Kecamatan Sipahutar merupakan sentra produksi tanaman nanas di Kabupaten Tapanuli Utara. Kecamatan Sipahutar memiliki luas area tanaman nanas 1.872,98 Ha, asumsi untuk satu hektar jumlah tanaman nanas rata-rata 45.000 pohon, maka jumlah bahan baku pasca panen yang berupa limbah mencapai $45.000 \mathrm{~kg}$ dengan asumsi $1 \mathrm{~kg}$ daun sama dengan 1 pohon nanas, sehingga ketersediaan bahan baku untuk industri manufaktur pengolahan serat cukup porspektif. Kecamatan Sipahutar mampu menghasilkan $1.556 .176 \mathrm{~kg}$ serat daun nanas (Subagyo, 2012).

Setiap 2 atau 3 kali panen, tanaman nanas lama yang sudah tidak berproduksi lagi harus diganti dengan tanaman nanas yang baru sedangkan daunnya dibuang sebagai limbah dari petani nanas. Pembongkaran tanaman nanas dilakukan secara bergilir dengan tiap 1 hektar lahan menghasilkan $45.000 \mathrm{~kg}$ daun nanas, jadi ketersediaan limbah sebagai bahan baku selalu terpenuhi.

Limbah daun nanas dapat diolah menjadi serat dengan menggunakan mesin decorticator. Mesin decorticator merupakan pemisah serat dan daging daun nanas yang terdiri dari suatu cylinder atau penggiling yang dapat berputar pada porosnya (Hidayat, 2008). Teknologi hasil inovasi mesin decorticator dengan rancangan sistem pemisahan serat dan daging daun nanas dengan cara yang mudah dan cepat.

Permukaan cylinder dibubut agar permukaan lebih kasar yang akan menimbulkan proses pengelupasan dan pemukulan (beating action) pada daun nanas, saat cylinder berputar (Doraiswarmy \& Chellamani, 1993). Gerakan perputaran cylinder dilakukan menggunakan motor listrik.

\section{Bahan dan Metode}

Pembuatan rancang bangun mesin decorticator dilaksanakan di bengkel Unimed pada bulan April - Mei 2019. Bahan yang digunakan pada pembuatan rancang bangun mesin decorticator tertera pada Tabel 1 .

Tabel 1. Alat dan Bahan pembuatan mesin decorticator

\begin{tabular}{cll}
\hline No. & Nama Bahan & Nama Alat \\
\hline 1 & Besi siku bolong & Grinda tangan \\
2 & Besi as padat & Mesin gergaji \\
& (Penggiling) & duduk \\
3 & Penyambung siku & Dinamo \\
4 & V-belt & Mesin bubut \\
5 & Bearing & Mesin las \\
6 & Mur dan baut & Motor listrik \\
7 & Plat seng & Pulley penggerak \\
8 & Spur Gear & Pulley ganda \\
& & Pulley \\
\hline
\end{tabular}

Pembuatan mesin decorticator dilakukan dengan diagram alir seperti yang tertera pada Gambar 1.

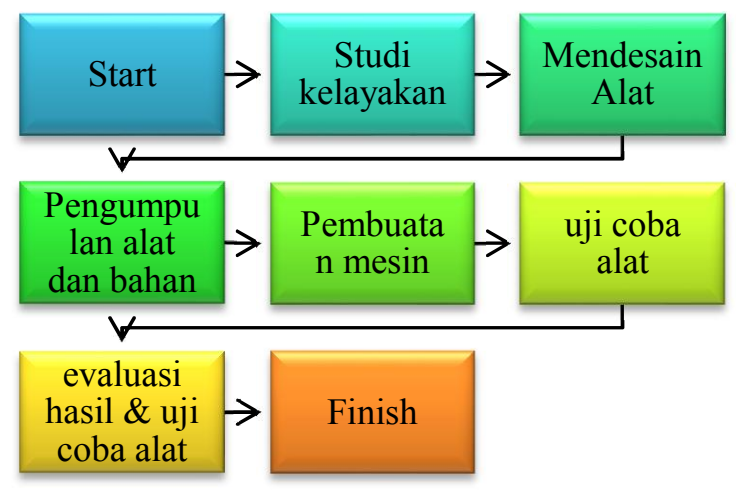

Gambar 1. Diagram alir pembuatan mesin decorticator.

a. Studi kelayakan

Studi kelayakan (feasibility study) merupakan bahan pertimbangan dalam mengambil keputusan, apakah menerima atau menolak dari suatu gagasan usaha/proyek yang direncanakan (Wijana et al., 2016).

b. Mendesain mesin

Mesin didesain dengan menggunakan software solidwork untuk dapat dirancang sistem yang lebih akurat, efisien, dan praktis. 
Desain yang dibuat berupa mesin decorticator dengan dimensi: $\mathrm{T}=50 \mathrm{~cm} \times \mathrm{L}=50 \mathrm{~cm} \times \mathrm{P}=25$ $\mathrm{cm}$. Gambar rancangan untuk tampak depan diperlihatkan pada Gambar 2.

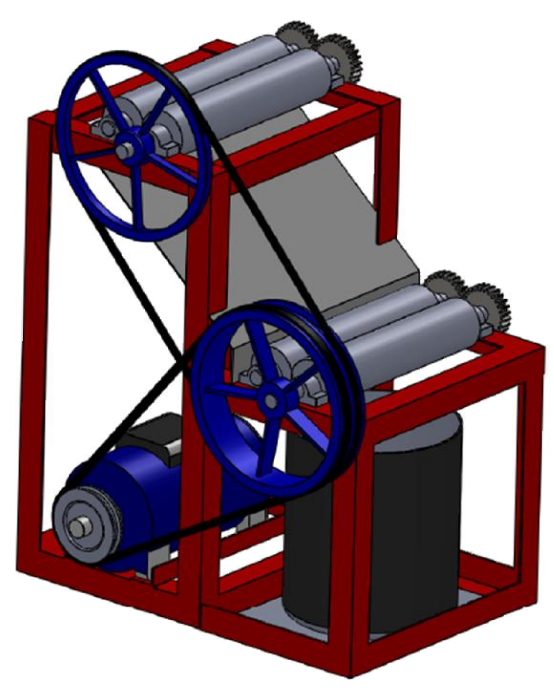

Gambar 2. Desain mesin decorticator.

c. Pengumpulan alat dan bahan

Pengumpulan alat dan bahan dilakukan di berbagai lokasi yang berbeda di Kota Medan. Untuk mendapatkan alat dan bahan yang diperlukan diperoleh pada tempat tertentu seperti di Jl. Pancing, Jl. Letda Sujono, Jl. AR Hakim, Jl. Gatot Subroto, Jl. Prof. H.M Yamin, Jl. Pandu.

\section{d. Pembuatan mesin decorticator}

Proses pembuatan mesin decorticator secara ringkas tertera pada diagram alir Gambar 3.

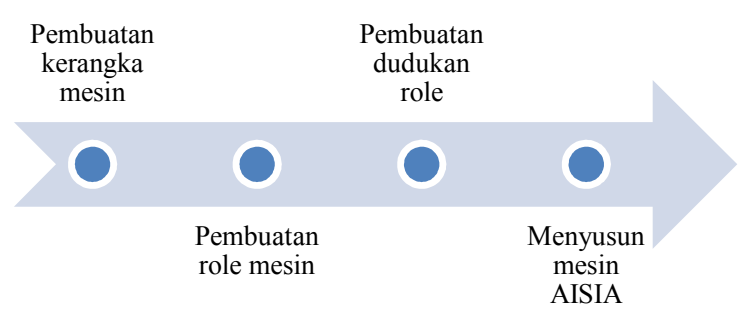

Gambar 3. Diagram alir pembuatan mesin decorticator.

Pembuatan alat dimulai dari penyediaan alat dan bahan, pembuatan kerangka alat, pembuatan penggilingan, pemasangan bearing, pembuatan rangka dudukan penggiling, pembuatan turunan daun dari plat, pemasangan penggiling, motor listrik, pulley dan $V$-belt.

\section{e. Teknik pengumpulan data}

Data yang dikumpulkan berupa data kuantitatif dari hasil uji coba mesin. Pengujian mesin dilakukan dengan memasukkan daun nanas ke penggiling 1 dan penggiling 2. Data yang dikumpulkan berupa data kapasitas mesin yang telah dirancang.

\section{f. Teknik Analisis Data}

Data dianalisis untuk menguji tingkat kecepatan mesin yang dihasilkan serta tekanan yang diberikan kepada daun nanas.

\section{Hasil dan Pembahasan}

1. Komponen-komponen utama alat

Mesin decorticator memiliki komponenkomponen utama sebagaimana ditunjukkan Gambar 4 yang digunakan adalah:

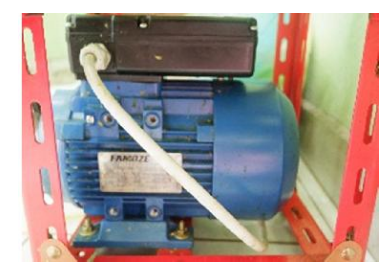

Motor Listrik

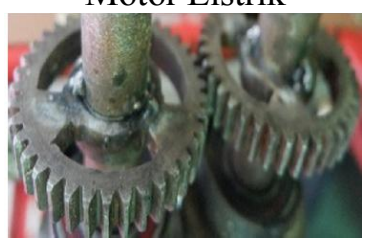

Gear

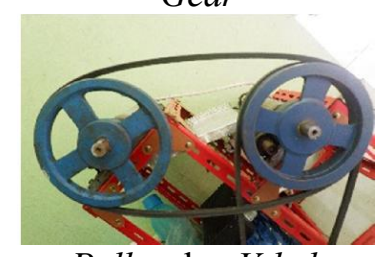

Pulley dan V-belt

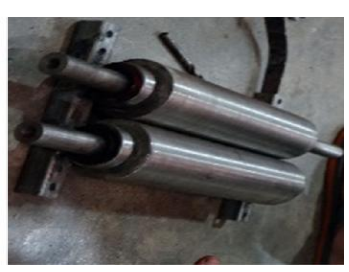

Penggiling

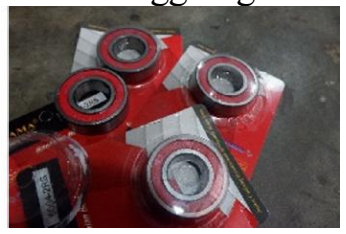

Bearing

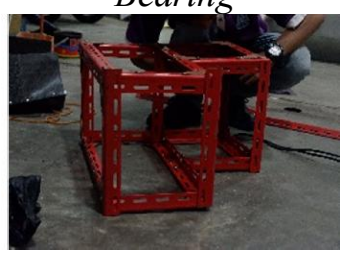

Kerangka
Gambar 4. Komponen-komponen utama alat.

a. Motor Listrik

Motor $1400 \mathrm{rpm}$ sebagai penggerak utama role/penggiling. Motor listrik digunakan untuk mengubah dari energi listrik menjadi energi mekanik dalam bentuk energi gerak dengan prinsip elektromagnetis (Halliday et al., 2011). 
b. Penggiling

Penggiling yang menerapkan prinsip dua roda berporos yang dipasang berimpit dan berguna untuk melakukan penggilingan daun nanas agar bisa menghasilkan serat.

c. Gear

Merupakan salah satu komponen penggerak pada putaran poros untuk di transmisikan ke conveyor belt (Harahap, et al., 2018).

d. Bearing

Merupakan komponen untuk mengurangi gesekan dari suatu putaran, sehingga membuat putaran roda dan conveyor belt lancar (Harahap et al., 2018).

e. Roda gigi

Merupakan salah satu komponen yang menerima putaran transmisi dari rantai.

f. Pulley

Merupakan suatu alat mekanis yang digunakan sebagai pendukung pergerakan tali pulley untuk mengubah arah dari gaya yang diberikan dan mengirimkan gerak rotasi.

g. Kerangka

Merupakan alat untuk menempatkan atau menopang motor listrik, penggiling serta pulley.

2. Pembuatan mesin decorticator

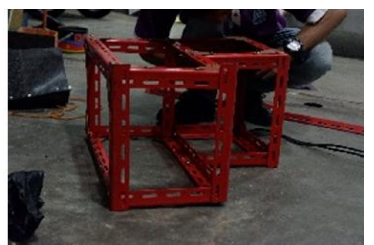

Pembuatan kerangka

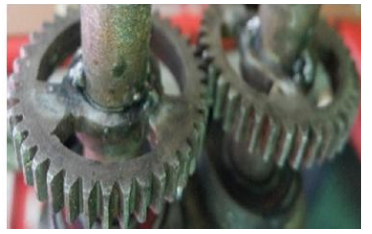

Pengesalan gear

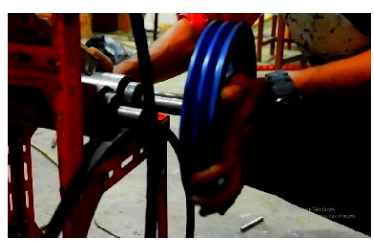

Pemasangan Pulley dan $V$-Belt

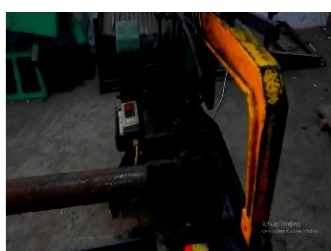

Pemotongan besi as

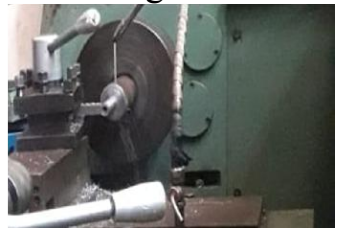

Pembubutan besi as

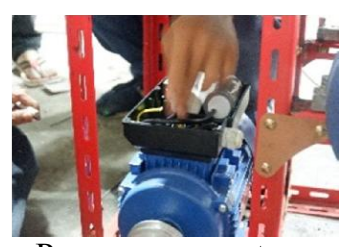

Pemasangan motor listrik
Gambar 5. Proses pembuatan mesin decorticator.
Kerangka alat terbuat dari besi siku bolong dengan dimensi: $\mathrm{T}=50 \mathrm{~mm} \times \mathrm{L}=50 \mathrm{~mm}$ $\times \mathrm{P}=25 \mathrm{~mm}$. Penggiling dibuat dengan mesin bubut Gambar 5.

Kerangka alat terbuat dari besi siku bolong dengan dimensi: $\mathrm{T}=50 \mathrm{~mm} \times \mathrm{L}=50 \mathrm{~mm}$ $\times \mathrm{P}=25 \mathrm{~mm}$. Siku bolong dipotong disambung menggunakan penyambung siku dan dilas, Penggiling dibuat dari bahan dasar besi as padat yang dipotong dan dibubut menggunakan mesin bubut ysng ditunjukkan pada Gambar 5. Komponen lainnya berupa penggiling dengan dudukan penggiling terbuat dari bearing, gear, yang disambung dan digabungkan ke kerangka besi dengan cara dilas. Selanjutnya dipasang pulley dan diukur ukuran $V$-belt setelah pulley dipasang. Mesin decorticator dapat dilihat pada Gambar 6.

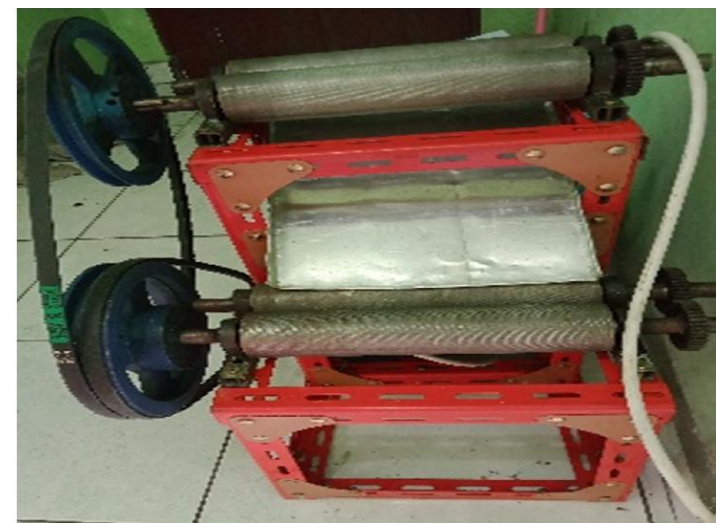

Gambar 6. Mesin decorticator.

3. Sistem kerja mesin decorticator

Mesin decorticator terdiri dari suatu penggiling atau penggiling yang dapat berputar pada porosnya. Pada permukaan penggiling dibubut agar permukaan sedikit kasar sehingga bisa merobek kulit daun nanas yang akan menimbulkan proses perobekan, pemukulan (beating action) pada daun nanas, saat penggiling berputar (Doraiswarmy \& Chellamani, 1993). Gerakan perputaran roll digerakan menggunakan motor listrik. Saat roll berputar, daun-daun nanas akan dijatuhkan dan diputar oleh penggiling yang ditunjukkan pada Gambar 7.

Penggiling akan mengarahkan daun nanas jatuh ke plat dan plat mengarahkan ke penggiling kedua, penggiling kedua akan menggiling kembali serat daun nanas dengan 
tekanan yang lebih besar sehingga didapat serat daun nanas.

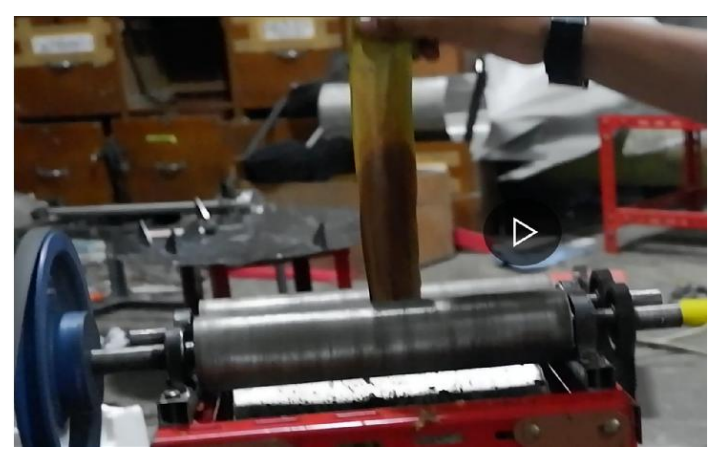

Gambar 7. Serat daun nanas digiling.

Karena daun-daun nanas yang digiling mengalami proses pengelupasan dan pemukulan yang dilakukan oleh penggilingpenggiling selama berputar, maka kulit daun ataupun zat-zat perekat (gummy substances) yang terdapat disekitar serat akan terpisah dengan seratnya (Hidayat, 2008). Kecepatan putaran penggiling dan jarak seting antara dua penggiling akan mempengaruhi terhadap keberhasilan dan kualitas serat yang dihasilkan. Untuk memudahkan pemisahan zatzat yang ada di sekitar serat dan menghindari kerusakan pada serat, proses decortikasi sebaiknya dilakukan pada kondisi daun dalam keadaan segar dan basah (wet condition). Daun-daun nanas yang telah mengalami proses dekortikasi, kemudian dicuci dan dikeringkan melalui sinar matahari.

\section{Ujicoba alat}

Mesin decorticator diuji coba terlebih dahulu untuk melihat berhasil atau tidaknya mesin menggiling hingga menghasilkan serat.

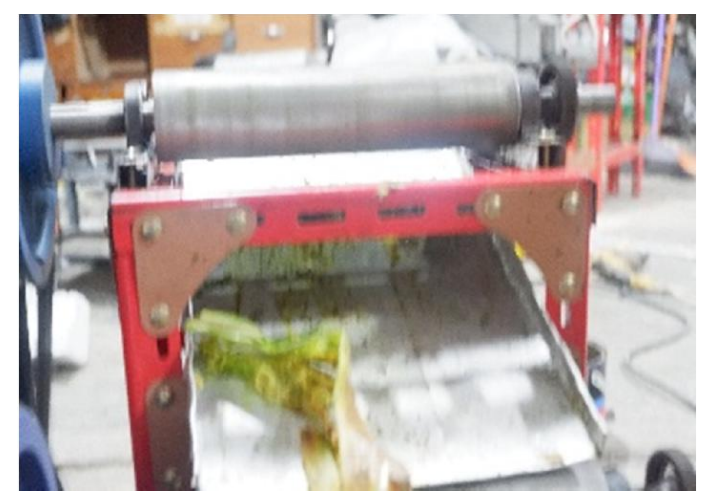

Tabel 3. Produksi mesin decorticator

\begin{tabular}{cccl}
\hline No. & Penggiling & rpm & $\begin{array}{c}\text { Produksi } \\
\text { kg/jam }\end{array}$ \\
\hline 1 & Penggiling 1 & 600 & 0,096 \\
2 & Penggiling 2 & 1000 & 0,12 \\
\hline
\end{tabular}

Gambar 8 menunjukkan proses mesin yang sedang menggiling daun nanas. Hasil yang diperoleh yaitu daun nanas menjadi serat. Hasil penggujian mesin decorticator diperolah data pada Tabel 3.

Hasil memperlihatkan bahwa dalam setiap penggiling meimiliki kecepatan dan produksi yang berbeda. Pada penggiling 1 mampu memproduksi $0,096 \mathrm{~kg} / \mathrm{jam}$. Penggiling 2 memproduksi $0,12 \mathrm{~kg}$. Mesin decorticator mampu bekerja dalam sehari dengan waktu operasi selama 5 jam.

\section{Kesimpulan dan Saran}

Berdasarkan hasil penelitian ini, maka dapat disimpulkan yaitu:

1. Mesin decorticator serat daun nanas telah bekerja secara maksimal dengan jumlah rata-rata produksi $0,12 \mathrm{~kg} / \mathrm{jam}$.

2. Mesin decorticator serat daun nanas memiliki dua penggiling yang dapat mengepress serat daun nanas secara bertahap hingga menjadi serat daun berupa bahan baku tekstil.

3. Dalam pembuatan mesin decorticator serat daun nanas selanjutnya, agar memperhatikan kecepatan putaran dan kerapatan kedua penggiling agar memperoleh hasil yang lebih baik.

\section{Ucapan Terima Kasih}

Tim mengucapkan terimakasih kepada RISTEKDIKTI yang mendanai kegiatan PKM-T, Bapak Rektor Universitas Negeri Medan dan jajarannya, mitra petani nanas desa Onan Runggu III Kecamatan Sipahutar Kabupaten Tapanuli Utara, kepala bengkel Fakultas Teknik Universitas Negeri Medan yang telah bekerja sama dengan Tim didalam pembuatan teknologi mesin decorticator serat daun nanas.

Gambar 8. Menggiling daun nanas. 


\section{Daftar Pustaka}

Doraiswamy I., Chellamani, P., 1993. Pineapple Leaf Fibres, Textile Progress. 24 (1) pp.

Halliday, D., Resnick, R., \& Jearl Walker, J., 2011, Fundamental of Physics, edisi 9, , John Wiley \& Sons, Hoboken.

Harahap, M.F., Marpaung, M.A., Pranata, J.D., Siregar, B.M., 2018. Inovasi Penyapu Sampah Menggunakan Becak Tenaga Listrik di Kota Medan. Piston. 2 (2):5359.

Hidayat, P., 2008. Teknologi Pemanfaatan Serat Daun Nanas Sebagai Alternatif
Bahan Baku Tekstil. Teknoin, 13(2): 3135.

Subagyo, A., 2012. Strategi Pengembangan Industri Serat Alam Daun Nanas untuk Meningkatkan Taraf Hidup Masyarakat. Jurnal Inovasi dan Kewirausahaan. $1(1): 23-28$.

Wijana, M., Triadi, A.A., A, Anwar, L.S., 2016. Studi Kelayakan Penggunaan Mesin Diesel dengan Metode Break Even Point (BEP) dan Analisis Sensitivitas pada Pltd (Studi Kasus: PT PLN Persero Sektor Pembangkitan Lombok PLTD Ampenan). Dinamika Teknik Mesin. 6 (1): 60-68. 